www.jmscr.igmpublication.org Impact Factor 5.84

Index Copernicus Value: 83.27 ISSN (e)-2347-176x ISSN (p) 2455-0450 crossref DOI:_https://dx.doi.org/10.18535/jmscr/v5i5.19

\title{
Differentiation of Benign and Malignant Breast Lesions Based on Ultrasound Criteria
}

\author{
Authors \\ Usha Kumari K $^{1}$, Sophy Susan Manuel $^{2}$ \\ ${ }^{1}$ Department of Radiodiagnosis, Government Medical College, Trivandum, Kerala, India \\ ${ }^{2}$ Present address: Division of Imaging, Metro Scans and Laboratary, Kollam, Kerala India \\ Former resident, Department of Radiodiagnosis, Government Medical College, Trivandum, Kerala, India \\ Email: ushakunjuramandr@gmail.com
}

\begin{abstract}
Aim: To evaluate the usefulness and accuracy of ultrasound imaging for distinguishing between benign and malignant breast masses, with FNAC or biopsy results as reference standard in a study population based in South India.

Materials and Methods: The records of breast ultrasound examination findings of 50 patients with solid breast masses were retrospectively reviewed. Criteria such as size, shape of the lesion, circumscribed or irregularity of margins such as indistinct, angular, microlobulate or spiculated, posterior enhancement or shadowing, calcifications, echo pattern, associated features mainly duct changes and W/AP ratio were evaluated and a diagnosis reached based on ultrasound criteria. Gold standard was kept as FNAC or biopsy.

Results: The sensitivity of breast US for malignancy was $96 \%$, specificity $85 \%$, positive predictive value $94 \%$, negative predictive value $92 \%$ and accuracy 93\%, Among the benign criteria marked hyperechogenicity and ellipsoid shape had 100\% negative predictive value. Negative predictive value of 3 or fewer gentle lobulations and thin echogenic capsule was $87.5 \%$ each. $75 \%$ of fibroadenomas showed W/AP ratio $>1.4$ and $93 \%$ of malignant lesions showed W/AP ratio $<1.4$ ( $p$ value $<.001$ statistically significant).

Conclusion: The data confirm that using strict sonographic criteria it is possible differentiate benign from malignant lesions with confidence. Furthermore, applying these criteria can obviate need for biopsy in a group of benign solid breast lesions.

Keywords: Breast carcinoma, breast neoplasms, sonography, positive predictive value, negative predictive value.
\end{abstract}

\section{Introduction}

Breast Carcinoma is the leading cause for cancer deaths in women both in the developed and less developed world. Worldwide over 522000 women died in 2012 due to breast cancer according to Globacon 2012. In India alone 145000 incident cases and 70000 deaths are estimated to have occurred during that year. It is critical to obtain a definitive diagnosis as early as possible.
Ultrasound being non invasive is extensively used in breast imaging. Advantages of the hand-held real-time technique include supine patient positioning, flexible probe orientations, improved resolution of higher frequency transducers and compression techniques to assess tissue compliance and fixation. ${ }^{[1]}$

Starvos et al ${ }^{[2]}$ in 1995 demonstrated that solid breast lesions could be confidently characterized as 
benign or malignant with high-resolution grays-scale US imaging.

Later investigators ${ }^{[3],[4]}$ also supported these findings and these features formed an vital component of the Breast Imaging and Reporting Data System ${ }^{[5]}$.

Currently ultrasound is indicated for evaluating palpable abnormalities and characterizing masses detected at mammography and magnetic resonance imaging. Ultrasound may also be used as an adjunct for breast cancer screening modality in women with dense breast tissue and a negative mammogram. Moreover Ultrasound is the primary imaging modality in females under 30 years old with a palpable lump or focal mastalgia with a sensitivity and negative predictive value of nearly $100 \%$. ${ }^{[6]}$

In this retrospective study an attempt was made to evaluate the usefulness and accuracy of ultrasound imaging for distinguishing between benign and malignant solid breast masses, with FNAC or biopsy results as reference standard.

\section{Materials and Methods}

The records of breast ultrasound examinations of 50 women with solid breast masses between August 1998 and December 2000 to the radiodiagnosis department of government medical college trivandrum. were retrospectively reviewed. Majority of the patients were referred from the surgery department, government medical college, Trivandrum and the remaining from Regional Cancer Centre, Trivandrum

After taking relevant clinical history and conducting physical examinations, the ultrasound evaluation was performed with ALOKA SSD 2000 unit with 7.5 MHZ linear array probe and $5 \mathrm{MHZ}$ convex array probe. All scans were performed by the same radiologist and the findings recorded. Each breast was examined by a quadrant wise approach covering all four quadrants and the axillary extension of the breast. Patients were scanned supine with the position adjusted to flatten out the breast. The ipsilateral arm was extended behind the head so as to assess the inner quadrants.
Similarly to evaluate the upper outer quadrant, the patients were turned to the opposite side in a slight oblique position. The survey-search technique ${ }^{[1]}$ of examining each quadrant separately in a vertical or transverse sweep was utilized.

Varying compression was applied, in the evaluation of solid masses according to their location and size for optimal imaging. Images were obtained in radial fashion with the nipple as the center of the radius to examine ductal anatomy. The nipple and areola complex was imaged by keeping the transducer adjacent to the nipple and beam angled to the retroareolar area.

Only the data of patients without a prior history of biopsy were included in the study. Patients with advanced carcinoma of the breast (stage II B and above) were excluded from the study. Gold standard was kept as FNAC or biopsy reports.

Review of the findings of real time sonography such as size of the lesion, shape, echogenicity, margins, spiculation, calcification, shadowing, duct extension, micro lobulations, width to antero posterior ratio (W/AP ratio) etc was done and predictability calculated. The accuracy of ultrasound in characterizing breast lumps and to correlate the ultrasound findings with the pathology results was also evaluated.

The W/AP ratio denotes width to anteroposterior ratio, where $\mathrm{W}$ is the longest diameter parallel to the skin and AP is the anteroposterior diameter, which is the growth perpendicular to the skin. W/AP quantifies the degree of elongation of the tumour

\section{Results}

The youngest patient in this study was 20yrs and the oldest one was 71yrs old. Majority (40\%) of patients were in the 40-49yr age group followed by $18 \%$ in $50-59 \mathrm{yr}$ range, $16 \%$ in $30-39 \mathrm{yr}$ range and less than $10 \%$ in remaining age groups.

Of the benign lesions highest percentage (43.8\%) was in 40-49yr age group, $31 \%$ in $30-39 y r$ range and $25 \%$ in $20-29 \mathrm{yr}$ range. None of the patients above 50 included in the study had benign lumps. 


\section{Figure 1}

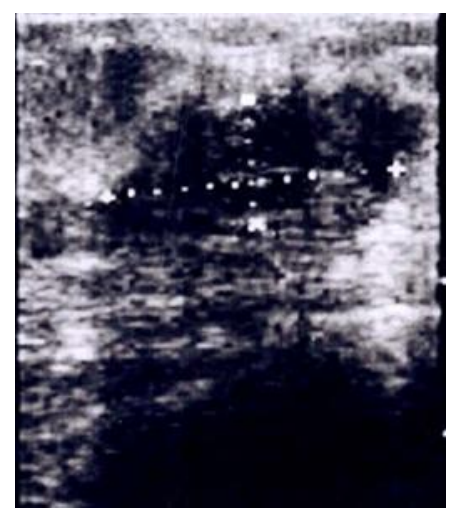

Ultrasound image of malignant mass showing spiculatons, angular margins, distal shadowing, duct extension-

Figure 2

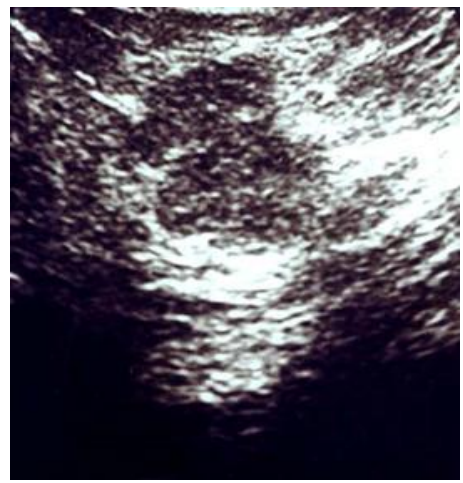

Ultrasound image of malignant mass demonstrates microlobulations, hypoechogenicity, angular margins

In the case of malignant lesions to the highest percentage was in 40 49yr age group (38.2\%) followed by $26.5 \%$ in $50-59 \mathrm{yr}$ range, $11.8 \%$ were in 60-69yr age group and less than $10 \%$ in rest of the age groups. All patients above 50 yrs. Who underwent the study had malignant lumps. The lowest percentage of malignancy was in $20-29 \mathrm{yr}$ age group $(5.9 \%)$. The youngest one with malignancy was a $28 \mathrm{yrs}$ old patient.

$54 \%$ of the breast lumps were located in the upper outer quadrant. $20 \%$ in upper inner quadrant, $8 \%$ each in either lower quadrants, $2 \%$ in subareolar region and $4 \%$ in upper outer and inner quadrants. In remaining $4 \%$, there was bilateral involvement. According to clinical diagnosis $26 \%$ of the lesions were benign, $58 \%$ were malignant, and $16 \%$ were of doubtful malignancy.

Among the criteria for benignity (markedly hyperechoic, ellipsoid shape, 3 or fewer gentle lobulations, thin echogenic capsule, absence of malignant findings) $87.5 \%$ of the lesions showed ellipsoid shape and absence of malignant findings. $62.5 \%$ showed thin echogenic capsule, $25 \%$ of the lesions were markedly hyperechoic $12.5 \%$ showed 3 or fewer gentle lobulations.

Figure 3.

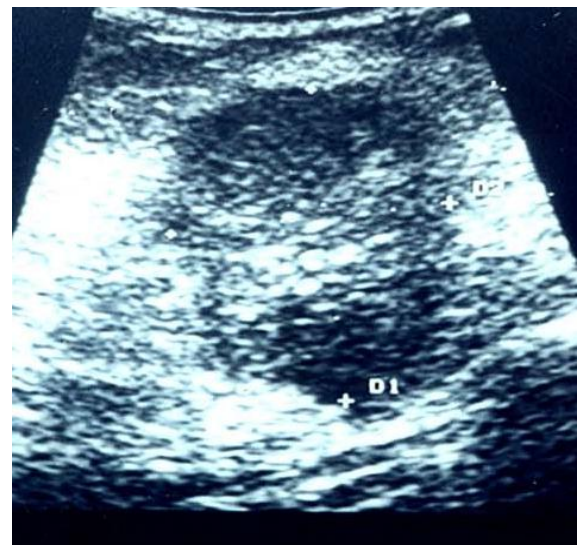

Ultrasound image of malignant mass depicting AP diameter more than transverse diameter indicating non parallel orientation to the skin.

Among the 9 criteria denoting malignancy, $62 \%$ of the lesions showed marked hypoechogenicity. More than half of the lesion had spiculated edges and angular margins (52\% and 54\% respectively). Half of the lesions were taller than wide and exhibited posterior acoustic shadowing. Calcification could be detected only in 9 lesions (18\%). $28 \%$ of the lesions showed microlobulation. 2 lesions showed duct extension and branch pattern.

Good ultrasound pathological correlation was obtained in benign lumps. 12 breast lumps were diagnosed as benign (8 fibroadenomas and 4 benign breast change). One lump which was diagnosed as benign, based on 3 or fewer gentle lobulations, thin echogenic capsule and absence of malignant findings turned out to be malignant.

Of the 33 cases considered malignant based on ultrasound features 2 lumps turned out to be benign. One showed calcifications and microlobulation and other one was markedly hypoechoic with posterior acoustic shadowing and microlobulations.

Of the 8 cases of fibroadenoma, 6 showed W/AP ratio $>1.4 .31$ of 33 malignant lumps showed a 
W/AP ratio <1.4.All 4 cases diagnosed as benign breast change was confirmed on HPR. 5 cases were unequivocal simple cysts and follow up was advised.

The opposite breast was normal in all cases except in one benign breast change were there was bilateral involvement.

In three cases axilla showed lymph nodes. Clinically it was palpable in only one case. Ultrasound showed them to be rounded in shape and echogenic hilum could not be identified. Diagnosis offered in all these cases were malignancy. One of this turned out to be benign, with reactive change in axillary lymphnode.

\section{Distribution According to age}

\section{Bar diagram}

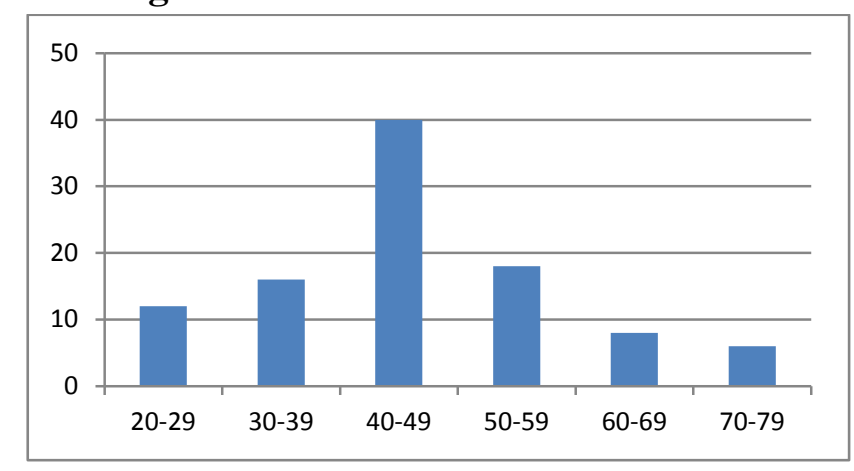

Table I Distribution according to clinical diagnosis

\begin{tabular}{|l|c|c|}
\hline Clinical Diagnosis & Number & Percentage \\
\hline Benign & 13 & $26 \%$ \\
\hline Malignant & 29 & $58 \%$ \\
\hline ? Malignant & 8 & $16 \%$ \\
\hline
\end{tabular}

Table II Age wise distribution of ultrasound diagnosis

\begin{tabular}{|l|c|c|c|c|}
\hline \multirow{2}{*}{ Age } & & \multicolumn{2}{|c|}{ USG } & Total \\
\cline { 3 - 5 } & & Benign & Malignant & \\
\hline \multirow{2}{*}{$20-29$} & Count & 4 & 2 & 6 \\
\cline { 2 - 5 } & $\%$ with USG & $23.53 \%$ & $6.06 \%$ & $12 \%$ \\
\hline \multirow{2}{*}{$30-39$} & count & 5 & 3 & 8 \\
\cline { 2 - 5 } & $\%$ with USG & $29.41 \%$ & $9.09 \%$ & $16 \%$ \\
\hline \multirow{2}{*}{$40-49$} & count & 8 & 13 & 21 \\
\cline { 2 - 5 } & $\%$ with USG & $47.06 \%$ & $39.4 \%$ & $42 \%$ \\
\hline \multirow{2}{*}{$50-59$} & count & 0 & 9 & 9 \\
\cline { 2 - 5 } & $\%$ with USG & & $27.27 \%$ & $18 \%$ \\
\hline \multirow{2}{*}{$60-69$} & count & 0 & 4 & 4 \\
\cline { 2 - 5 } & $\%$ with USG & & $12.12 \%$ & $8 \%$ \\
\hline \multirow{2}{*}{$70-79$} & count & 0 & 2 & 2 \\
\cline { 2 - 5 } & $\%$ with USG & & $6.06 \%$ & $4 \%$ \\
\hline & Total & 17 & 33 & 50 \\
\hline & & $100 \%$ & $100 \%$ & $100 \%$ \\
\hline
\end{tabular}

\section{Discussion}

The nodules evaluated in this study were typical of those seen in every day practice. This study does not contain a disproportionate percentage of advanced lesions. In this study breast lumps whether they are benign or malignant were found mainly in the 40-49 yr age group.

Among the five simple cysts 4 were in the 40-49yr and 1 was in 30-39yr range. According to literature cysts are very common finding in women during the involution phase (35-50 years). Simple cysts are characterized with $100 \%$ accuracy ${ }^{[7],[8]}$ as long as they are not too small $(<5 \mathrm{~mm}$ in size $)$ or not too deep.

Fibroadenomas are more common before 25 to 30 years of age and it is the most common benign tumor of female breast. In this study most of them were in patients below 40 years. In this study benign breast change was also found more commonly in 40-49yr age group as in the literature. Carcinoma is the main breast disease encountered in our study. The youngest one with malignancy was a 28yrs old patient and the lowest percentage of malignancy was in 20-29yr age group. Like other benign breast lumps malignant lumps were also more common in $40-49 y$ r age group. $60 \%$ of breast carcinomas were located in the upper outer quadrant. It is a well accepted fact that more than $50 \%$ of carcinomas are located in the upper outer quadrant probably due to the larger concentration of terminal duct lobular units. Size of the lesions varied greatly among cases included in this study, and size was not a significant factor in deciding the nature of the lesion. Another parameter that was correlated to size and also to shape was width to anteroposterior ratio or the W/AP ratio were $\mathrm{W}$ is the longest diameter parallel to the skin and AP is the anteroposterior diameter, which is the growth perpendicular to the skin. W/AP quantifies the degree of elongation of the tumour. In this study $75 \%$ of fibroadenomas showed W/AP ratio $>1.4$ and $93 \%$ of malignant lesions showed W/AP ratio $<1.4$ ( $\mathrm{p}$ value $<.001$ statistically significant). Data reported in literature are controversial. In one of the series using the threshold of $1.4,86 \%$ of 
fibroadenomas had W/AP ratio $>1.4$ when $100 \%$ of carcinomas had a ratio $<1.4$. However, in a study by Rahbar et al where One hundred sixty-two consecutive solid masses with a tissue diagnosis were reviewed, when width-to-anteroposterior (AP) dimension ratio was greater than 1.4, 82 of 92 $(89 \%)$ were benign whereas when width-to-AP dimension ratio of 1.4 or less 28 of $70(40 \%)$ were malignant. ${ }^{[9]}$

Table V Distribution of individual benign criteria and negative predictive value of each characteristic

\begin{tabular}{|l|c|c|c|}
\hline & Number & Percentage & $\begin{array}{c}\text { Negative } \\
\text { predictive } \\
\text { value }\end{array}$ \\
\hline $\begin{array}{l}\text { Markedly } \\
\text { hyperechoic }\end{array}$ & 2 & $25 \%$ & 100 \\
\hline Ellipsoid shape gentle & 1 & 12.5 & 92.3 \\
\hline $\begin{array}{l}\text { 3/fewer echogenic } \\
\text { tabulations }\end{array}$ & 5 & 62.5 & 92.3 \\
\hline $\begin{array}{l}\text { Thin } \\
\text { capsule }\end{array}$ & 7 & 87.5 & 92.3 \\
\hline $\begin{array}{l}\text { Absence of malignant } \\
\text { findings }\end{array}$ & \multicolumn{3}{|l}{} \\
\hline
\end{tabular}

Table VI Distribution of individual malignant criteria and positive predictive value of each characteristic

\begin{tabular}{|l|c|c|c|c|}
\hline SLNo. & Criteria & Number & Percentage & $\begin{array}{c}\text { Positive } \\
\text { Predictive } \\
\text { value }\end{array}$ \\
\hline 1 & Spiculation & 26 & $52 \%$ & 100 \\
\hline 2 & $\begin{array}{c}\text { Taller than } \\
\text { wide }\end{array}$ & 25 & 50 & 100 \\
\hline 3 & $\begin{array}{c}\text { Angular } \\
\text { margins }\end{array}$ & 27 & 54 & 100 \\
\hline 4 & Shadowing & 25 & 50 & 96.5 \\
\hline 5 & Calcification & 9 & 18 & 90 \\
\hline 7 & Duct extension & 2 & 4 & 100 \\
\hline 8 & Branch pattern & 2 & 4 & 100 \\
\hline 9 & $\begin{array}{c}\text { Micro } \\
\text { tabulations }\end{array}$ & 14 & 28 & 87 \\
\hline
\end{tabular}

Table VII Distribution according to USG diagnosis

\begin{tabular}{|l|c|c|}
\hline $\begin{array}{l}\text { Ultrasound } \\
\text { diagnosis }\end{array}$ & Number & Percentage \\
\hline Benign & 17 & $34 \%$ \\
\hline Malignant & 33 & $66 \%$ \\
\hline Total & 50 & $100 \%$ \\
\hline
\end{tabular}

Table VIII Distribution according to HPR

\begin{tabular}{|l|c|c|}
\hline HPR & Number & Percentage \\
\hline Benign & 13 & $28.88 \%$ \\
\hline Malignant & 32 & $71.12 \%$ \\
\hline Total & 45 & $100 \%$ \\
\hline
\end{tabular}

Table IX Sensitivity, specificity, positive predictive value and negative predictive value of ultrasound of breast for malignancy

\begin{tabular}{|l|c|c|c|}
\hline $\begin{array}{l}\text { USG } \\
\text { classification }\end{array}$ & \multicolumn{2}{|c|}{ Histopathological findings } & Total \\
\hline Malignant & 31 & 2 & 33 \\
\hline Benign & 1 & 11 & 12 \\
\hline Total & 32 & 13 & 45 \\
\hline
\end{tabular}

Sensitivity-96\%, Specificity - 85\%, PPV - 94\%, NPV - 92\%, Accuracy - $93 \%$

In one of the patients who had markedly hypoechoic lump with posterior acoustic shadowing and microlobulations, the ultrasound diagnosis suggested was malignant breast lump with axillary lymph node involvement. Axillary lymph node was rounded and echogenic hilum was not identifiable. However, the biopsy report was fibroadenoma with reactive change in axillary lymph node.

Among the benign criteria marked hyperechogenicity and ellipsoid shape had $100 \%$ negative predictive value. Negative predictive value of $3 /$ fewer gentle lobulations and thin echogenic capsule was $87.5 \%$ each. First 2 findings closely corresponds to those reported in literature. [2] The NPV for hyperechogenicity and ellipsoid shape was 100 and $99.1 \%$ whereas 3/Fewer gentle lobulations and thin echogenic capsule had $99.2 \%$ and $98.8 \%$ in study conducted by Stavros et al.

Lesions with these Sonographic features of benign-appearing solid masses are commonly fibroadenomas or other benign masses and can often be safely followed. ${ }^{[10],[11]}$

Among malignant criteria; spiculation, taller than wide, angular margin, duct extension and branch pattern had a positive predictive value of $100 \%$. Positive predictive value of marked hypoechogenicity and shadowing was $96 \%$ and $96.5 \%$ respectively. Calcification had $90 \%$ positive predictive value and microlobulation had $87 \%$. All these figures were high when compared with 
various published data and this may be due to the small sample volume.

The positive predictive values for malignancy according to Stavros et $\mathrm{al}^{[2]}$ is $91.8 \%$ for spiculation, followed by $81.28 \%$ for taller than wide and $67.5 \%$ for angular margins. Posterior shadowing and branch pattern had similar PPV of 64.9 and $64 \%$ respectively. Hypoechogenicity $(60.1 \%$ )calcification(59.6\%)ductal extension (50.8) and microlobulations (48.2\%) had lesser positive predictive value.

In a study of Sonographic BI-RADS descriptors ${ }^{[10]}$ by observers using static images, features highly predictive of benign lesions include circumscribed margin $(90 \%$,$) , parallel orientation (78 \%$,$) , and$ oval shape $(84 \%$,). Sonographic BI-RADS descriptors in the study showing high predictive value for malignancy included spiculated margin $(86 \%$,$) , irregular shape (62 \%))$, and nonparallel orientation $\left(69 \%,{ }^{[12]}\right.$ which are comparatively low. A major role of targeted sonography is to improve the specificity of clinical and mammographic findings in carefully selected patients. That goal was met in a large percentage of cases in this study. The sensitivity of breast US for malignancy was $96 \%$, specificity $85 \%$, positive predictive value$94 \%$, negative predictive value-92\% and accuracy $93 \%$, compared to $98.4 \%$ sensitivity, $67.8 \%$ specificity, $99.5 \%$ negative predictive value, $40 \%$ positive predictive value and $72.9 \%$ accuracy of published data by Stavros et al. The high values are due to the small sample volume.

Limitations of this study include the small sample size. This study did not employ the BIRADS lexicon for characterization. However BIRADS US lexicon in $2003^{[13]}$ was found to have low to moderate inter observer agreement in description. This was especially for small masses and for malignant masses ${ }^{[14]}$

Although irregularity of margins of lesions and shadowing were found to be indicative of malignancy, non malignant pathology such as benign focal fibrous breast tissue or postoperative scars can also show these features. Similarly hyperechoic masses are frequently benign, yet malignant neoplasms like invasive ductal and invasive lobular carcinoma, lymphoma, and sarcoma can be hyperechoic. ${ }^{[15],[16],[17]}$.

\section{Conclusion}

The data confirm that using strict sonographic criteria it is possible differentiate benign from malignant lesions with confidence. Furthermore, applying these criteria can obviate need for biopsy in a population of benign solid breast lesions. However due to overlap in ultrasound features between benign and malignant masses, careful scanning techniques as well as correlation with clinical and mammography findings are essential to improve the accuracy.

\section{References}

1. Rubin E,Miller VE,Berland LL,Han SY,Koehler RE,Stanley RJ.Hand-held real-time breast sonography. AJR Am J Roentgenol.1985 Mar;144(3):623-7.

2. StavrosAT, ThickmanD, RappCL, DennisMA, ParkerSH, SisneyGA.Solid breast nodules: use of sonography to distinguish between benign and malignant lesions.Radiology1995;196(1):123-134.

3. Mainiero MB, Goldkamp A, Lazarus E, Livingston L, Koelliker SL, Schepps B, Mayo-Smith WW. Characterization of breast masses with sonography: can biopsy of some solid masses be deferred?J Ultrasound Med2005;24(2):161-167.

4. GrafO, HelbichTH, HopfG, GrafC, Sickles EA.Probably benign breast masses at US: is follow-up an acceptable alternative to biopsy?Radiology2007;244(1):87-93.

5. MendelsonEB, BaumJK, BergWA, MerrittCR, RubinE.Breast Imaging Reporting Data System.BI-RADS: Ultrasound. Reston, Va:American College of Radiology,2003.

6. Loving VA, DeMartini WB, Eby PR, Gutierrez RL, Peacock S, Lehman CD. Targeted ultrasound in women younger than 30 years with focal breast signs or 
symptoms: outcomes analyses and management implications. AJR Am J Roentgenol 2010;195(6):1472-147

7. Stavros AT. Breast ultrasound. Philadelphia, Pa: Lippincott, Williams \& Wilkins, 2004 google books p286

8. Hilton SV, Leopold GR, Olson LK, Willson SA. Real-time breast sonography: application in 300 consecutive patients. AJR Am J Roentgenol 1986;147(3): 479-486

9. Rahbar G, Sie AC, Hansen GC, Prince JS, Melany ML, Reynolds HE, Jackson VP, Sayre JW, Bassett LW. Benign versus malignant solid breast masses: US differentiation. Radiology 1999; 213: 889-894.

10. Raza S, Chikarmane SA, Neilsen SS, Zorn LM, Birdwell RL. BI-RADS 3, 4, and 5 lesions: value of US in management followup and outcome. Radiology 2008;248(3):773-81

11. Harvey JA, Nicholson BT, Lorusso AP, Cohen MA, Bovbjerg VE. Short-termfollow-up of palpable breast lesions with benign imaging features: evaluation of 375 lesions in 320 women. AJR Am J Roentgenol 2009;193(6): 1723-1730.

12. HongAS, RosenEL, SooMS, BakerJA. BI-RADS for sonography: positive and negative predictive values of sonographic features.AJR Am J Roentgenol2005 ;184(4):1260-1265.

13. American College of Radiology, BI-RADS Committee. ACR BI-RADS Breast Imaging and Reporting Data System: Breast Imaging Atlas. 4th ed. Reston: American College of Radiology; 2003.

14. Abdullah N, Mesurolle B, El-Khoury M, Kao E. Breast imaging reporting and data system lexicon for US: interobserver agreement for assessment of breast masses. Radiology 2009;252(3):665-672

15. Adrada B, Wu Y, Yang W. Hyperechoic lesions of the breast: radiologic histopathologic correlation. AJR Am J Roentgenol 2013;200:W518-W530.

16. Linda A, Zuiani C, Lorenzon M, Furlan A, Girometti R, Londero V, Bazzocchi M. Hyperechoic lesions of the breast: not always benign.AJR Am J Roentgenol2011;196(5):1219-1224

17. SoonPS, VallentineJ, PalmerA, Magarey CJ, SchwartzP, MorrisDL.Echogenicity of breast cancer: is it of prognostic value?Breast2004;13(3):194-199. 